\title{
Transdisciplinaridade e práticas híbridas em saúde mental*
}

\section{Transdisciplinarity and hybrid practice in mental health}

\author{
Elizabeth M. F. Araújo Lima ${ }^{1}$, Maria Isabel Garcez Ghirardi ${ }^{2}$
}

LIMA, E. M. F. A.; GUIRARDI, M. I. G. Transdisciplinaridade e práticas híbridas em saúde mental. Rev. Ter. Ocup. Univ. São Paulo, v. 19, n. 3, p. 153-158, set./dez. 2008.

RESUMO: A necessidade de se propor novos dispositivos de atenção em saúde mental é um dos desdobramentos relativos à desinstitucionalização da loucura e à busca de implantar a Reforma Psiquiátrica no Brasil. Discutir modos de ação que privilegiem a complexidade da vida de pessoas em condição de vulnerabilidade e criar territórios de acolhimento às diversas e possíveis organizações subjetivas e sociais, tem sido a tarefa das equipes comprometidas com a constituição de práticas que sustentem a rede substitutiva de atenção. Aos profissionais de saúde mental é colocado o desafio de rever cotidianamente sua prática. Para equipes o desafio está em deslocar-se de uma organização multiprofissional para uma dinâmica marcada pela transdisiciplinaridade que se propõe a habitar fronteiras como estratégia de percursos em territórios híbridos. Neste artigo temos a intenção de refletir sobre esse desafio considerando as propostas da Reforma Psiquiátrica que demandam dinâmicas de trabalho inovadoras e provocam novos agenciamentos entre os saberes no campo da saúde mental.

DESCRITORES: Saúde mental. Trabalho.

* Este trabalho foi apresentado no X Congresso Brasileiro de Terapia Ocupacional: contextos, territórios e diversidade, realizado em maio de 2007, em Goiânia e re-trabalhado para publicação neste periódico.

1. Docente do Curso de Terapia Ocupacional da USP, doutora em Psicologia Clínica na Pontifícia Universidade Católica de São Paulo (PUC-SP), pós-doutora pelo Núcleo de Estudos da Subjetividade do Programa de Pós-Graduação em Psicologia Clínica da PUC/SP.

2. Docente do Curso de Terapia Ocupacional da USP, doutora em Psicologia Social e do Trabalho pelo Instituto de Psicologia da USP.

Endereço para correspondência: Rua Cipotânea, 51 Cidade Universitária . CEP: 05360-000. São Paulo, SP. E-mail: beth.lima@usp.br 


\section{Reforma Psiquiátrica e práticas híbridas}

$\mathrm{D}$ esde o $2^{\circ}$. Congresso de Trabalhadores de Saúde Mental, promovido pela Plenária $\mathrm{Na}$ cional de Trabalhadores de Saúde Mental, que aconteceu na cidade de Bauru, em São Paulo, o dia 18 de maio ficou definido como data comemorativa da luta Por uma sociedade sem manicômios. O Movimento Social que sustenta essa luta se constituiu graças ao esforço empreendido por trabalhadores, usuários de serviços de saúde mental e de suas famílias, e é protagonista na consolidação da Reforma Psiquiátrica Brasileira, que é hoje uma Política Pública de Saúde.

Para além de constituir-se como Política Pública e de Estado, pautada pelos princípios do SUS (Sistema Único de Saúde), a Reforma Psiquiátrica brasileira caracteriza-se por ser um processo social complexo que se constitui e que ganha materialidade em seu tempo histórico, envolvendo diversos atores e atravessado por culturas e por contextos distintos (AMARANTE, 2003). Sustentar o processo da Reforma Psiquiátrica no cotidiano, demanda a construção de dispositivos que respondam às necessidades e às exigências de novas práticas profissionais, além disso, é importante lembrar que esse processo depende de novas configurações na organização do trabalho que contribuam para a transformação da relação social com a loucura.

Nesse contexto, trabalhar em saúde mental implica compor equipes que, no cotidiano dos serviços, compreendam a complexidade intrínseca ao empenho de cuidar de pessoas cujas histórias de isolamento social e de sofrimento psíquico são tão diversas quanto intensas. Equipes que percebam a necessidade de evitar a lógica disciplinar que sustenta a violência do confinamento com práticas conservadoras de controle social. Deleuze nos lembra que,

(...) a crise do hospital como meio de confinamento, a setorização, os hospitais-dia, o atendimento a domicílio puderam marcar de início novas liberdades, mas também passaram a integrar mecanismos de controle que rivalizam com os mais duros confinamentos. (DELEUZE, 2000, p. 220).

Esses mecanismos de controle a que Deleuze faz referência corresponderiam a uma biopolítica (FOUCAULT, 2001), uma forma de poder que se constitui centrada no corpo-espécie, suporte de processos biológicos dinâmicos. Essa forma de poder pretende conhecer os mecanismos regulatórios da vida das populações a fim de estabelecer uma vigilância organizada sobre grupos identitários e identificáveis. Daí a importância, na sociedade de controle, das senhas (corporativas ou não), que marcam o acesso ou o impedimento aos espaços, aos serviços de assistência, aos postos de trabalho e, sobretudo, à informação. Também os usuários de serviços de saúde mental estão expostos a esses mecanismos de vigilância permanente os quais, por sua vez, tendem a contaminar igualmente as formas de organização do trabalho daqueles que supostamente têm o mandato social do cuidado em saúde.

No campo do trabalho em saúde mental, esse controle tende contribuir para a configuração de espaços disciplinares ou, quando muito, interdisciplinares, impedindo a porosidade de fronteiras profissionais que contribuiria para a organização de estratégias transdisciplinares de transformação institucional. Enclausurados em disciplinas, os profissionais tendem a realizar tarefas nas quais a repetição e as normatizações técnicas e burocráticas passam a desempenhar um papel preponderante sobre as necessidades e o sofrimento da pessoa que requer assistência. (SANDUVETTE, 2007).

Ao propormos um espaço de práticas híbridas, buscamos discutir elementos de ação cotidiana no trabalho, com potência para produzir fendas na estrutura disciplinar, abrindo uma disposição favorável a organizações de trabalho pautadas pela transdisciplinariedade. Essa abertura permitiria a criação de novas formas de cuidado em saúde mental, uma vez que as equipes e os equipamentos podem ser contaminados pela complexidade da existência e do sofrimento daqueles que necessitam desse cuidado. Na perspectiva de práticas híbridas, as especificidades profissionais são parte integrante de uma rede de conhecimento, de estratégias e de formas de ação que permitem a produção de novos saberes locais e de novas formas de cuidado (LIMA, 1999), uma vez que "a transdisciplinaridade implica a criação de um campo novo que idealmente seria capaz de desenvolver uma autonomia teórica e metodológica perante as disciplinas que o originaram" (ALMEIDA FILHO, 2005, p. 45).

\section{Campos de ação, disciplinas e transdiciplinaridade}

Atualmente um processo simultâneo de fragmentação e de homogeneização geopolítica e cultural tem caracterizado um mundo que responde à hegemonia econômica do modelo capitalista. Em meio a esse processo e fomentado por produções artísticas, filosóficas e científicas do século $\mathrm{XX}$, o pensamento complexo tem se apresentado como uma potente ferramenta, indispensável para abordar as questões de nosso tempo e que permite superar a lógica clássica e disciplinadora.

Uma disciplina é um foco ou lugar para olhar o 
mundo (GUERRA, 1998), que nos fornece um modo de compreensão, através de valores, métodos, conceitos e crenças compartilhadas. Esse modo de olhar para o mundo marca limites e recorta conhecimentos, constituindo uma área específica de pertencimento. Cada disciplina implica um determinado modo de operar, um método e um campo de ação. Por caracterizar-se como um modo de trabalho e um modo de compreensão, as disciplinas implicam o desenvolvimento de uma linguagem especializada que se torna a base do pensamento e da observação, identificando, classificando, categorizando fenômenos, selecionando o que é ou não relevante para aquele campo e, através de discussões internas estabelece parâmetros e conclusões particulares (BOURDIEU, 2004).

A organização do conhecimento em disciplinas permitiu um avanço considerável da ciência e um sucesso tecnológico e econômico que reforçou essa visão. Entretanto, ao permitir este avanço, o conhecimento disciplinar definiu espaços protegidos, restritos e restritivos, limitados à construção de modelos que produzem simplificações esquemáticas do real. As teorias científicas, seus modelos explicativos, nunca são o reflexo puro e simples de realidades objetivas; elas são co-produtos das estruturas do espírito humano e das condições sócio-culturais do conhecimento (MORIN, 1984). Contudo, ainda hoje a disciplinarização científica contribui para uma visão racional de um mundo estável e estático, em que avança um processo de especialização do conhecimento que implica em solucionar um tipo de problema e em especializar-se em um tipo de solução.

No campo da Saúde, por exemplo, o modelo disciplinar é insuficiente para responder à complexidade das causas que envolvem o sofrimento e o colapso da vida humana, diante de uma realidade de miséria, de violência, de depressão e de tantos problemas atuais que dificilmente seriam resolvidos por uma disciplina isolada (GUERRA, 1998). Na busca de enfrentar a complexidade intrínseca do sofrimento, o pensamento complexo propõe a construção de novas formas de organização, de síntese e de superação da produção disciplinar de conhecimento, voltando-se para o campo da interdisciplinaridade, marcando uma diferença fundamental, uma vez que, mais que uma categoria de conhecimento, a interdisciplinaridade é uma categoria de ação - é a arte do tecer um tecido bem trançado e flexível. Para Morin (1984) a atitude interdisciplinar não é apenas resultado de uma simples síntese, mas de sínteses imaginativas e as audazes.

Assim, se o modelo disciplinar busca definir frontei- ras, o projeto de modelo interdisciplinar busca vazar essas fronteiras de modo tal que disciplinas variadas possam se compor para abordar um tema que lhes é comum, tendo como horizonte a superação da dicotomia ciência e arte; a reflexão sobre a dicotomia cultura e ciência; a importância do embate objetividade/ subjetividade; a superação da dicotomia percepção/sensação; a investigação da dicotomia espaço/tempo e, assim alcançar a transdisciplinaridade (JUPIASSU, 1976).

No ano de 1986 aconteceu em Veneza um simpósio internacional que reuniu um representativo grupo de cientistas, filósofos, artistas e se constituiu num marco histórico na direção da transdisciplinaridade. Esse simpósio sobre "Ciência e as fronteiras do conhecimento" resultou na "Declaração de Veneza", um conjunto de seis recomendações para o desenvolvimento científico contemporâneo e para a reordenação da cartografia universitária que indicam a transdisciplinaridade como o percurso possível para enfrentar os desafios de nossa época (CARVALHO, 1992). É importante salientar que a transdisciplinaridade evita o domínio sobre as várias disciplinas e busca a abertura de todas elas àquilo que as atravessa e que as ultrapassa (FREITAS apud GALHEIGO, 1999), pois, se o projeto disciplinar distingue, separa, privilegia e consagra, a perspectiva transdisciplinar combina, engendra e agencia. A transdisciplinaridade refere-se a uma ampliação dos horizontes da pesquisa assumindo redes sociais cada vez mais numerosas, tornando-se uma "transversalidade entre a ciência, o social, o estético e o político" (GUATTARI, 1992, p. 23).

Segundo Galheigo (1999, p. 50) a interdisciplinaridade e os desdobramentos transdisciplinares que podem ter lugar nas práticas em saúde, chegam às equipes no "bojo da discussão dos direitos de cidadania e na busca de modelos de atenção que atendam às demandas sociais de formas menos fragmentada". No entanto a autora ressalta que as experiências de superação do modelo disciplinar nessas equipes são pouco permanentes e estão vulneráveis à óptica do mercado e ao seu aliado próximo, o corporativismo profissional que captura essas experiências e coloca as especialidades à conseqüente disputa pela conquista de espaços exclusivos de poder profissional. Dessa forma, as equipes de saúde resistem em abandonar a configuração disciplinar e em pautar suas ações pela complexidade cotidiana de um trabalho em saúde mental que não pode prescindir do espaço híbrido como um território de compartilhamento de saberes.

Resta ainda, a necessidade de criar caminhos que nos 
levem a operar não mais numa lógica binária e excludente, matriz da clínica da doença. Inventar práticas que comportem múltiplas dimensões da vida e da saúde, num espaço que deixa de ser um espaço higiênico e controlado para tornar-se passível de ser contaminado pelas contradições da vida cotidiana. Contaminação esta que tem origem nas perturbações e afetações da vida do dia-a-dia, nos seus diversos cenários, nos seus diversos contextos, e que envolve e atravessa a todos na construção coletiva da saúde. Vale dizer que, inventar práticas, conceber intervenções em saúde mental, tem como pressuposto um questionamento do papel social dos técnicos da equipe de saúde, a fim de investir na transformação das relações de trocas entre a equipe e de ousar configurações produtivas que se ajustem à constituição de um hibridismo profissional que se dá na confluência de diversos saberes.

Nas práticas em saúde isto implica num deslocamento do modelo médico para um modelo de saúde que articula interfaces com as ciências humanas e sociais. A diversidade discursiva presente no campo da saúde e a necessidade cada vez mais premente de um trabalho em equipe integrado e consistente já implica em deslocamentos importantes que desarranjam os campos disciplinares tradicionais e nos impulsionam para um diálogo interdisciplinar mais exigente e complexo (MÂNGIA, 1999).

\section{Outra economia simbólica na produção de territórios híbridos}

A economia solidária, enquanto alternativa à economia de mercado, tem sustentado muitas de nossas intervenções, talvez seja o momento de pensarmos como essa outra economia pode se realizar no processo de nossa produção profissional e na confluência de diversos saberes. E, de que maneiras ela pode alimentar a constituição de práticas híbridas, na medida em que permitiria superar as práticas disciplinares ao horizontalizar as relações de poder, criando formas de resistência aos sistemas de controle e de dominação vigentes no trabalho em saúde. Essa outra economia pode auxiliar no enfrentamento da dimensão epistemológica da Reforma Psiquiátrica brasileira, que se caracteriza pelo conjunto de problemas relativos à produção de saber e que implica na invenção de um novo marco teórico e de novos operadores conceituais. Criar dispositivos de atenção pautados pela complexidade da vida cotidiana demanda a produção de práticas sociais, que podem se constituir como saberes que definem novos paradigmas epistemológicos (AMARANTE, 2003).

Estamos diante de um desafio, ao tentar propor outra forma de conhecer marcada pela idéia de complexidade, cuja ambição é a de prestar contas das articulações, despedaçadas pelos cortes entre as disciplinas (MORIN, 2002). Nossas próprias configurações profissionais, individuais ou coletivas, são resultantes dessa possibilidade de trânsito e de confluência de alguns saberes, bem como da possibilidade ou da habilidade em operar esses diversos saberes de maneira a potencializar a ação prática, colocando em questão as configurações dos territórios e suas fronteiras.

Discutir fronteiras e territórios tem sido algo arriscado, perigoso mesmo, no mundo atual. Fronteiras têm sido freqüentemente tomadas como sinônimo de trincheiras. De espaços de polícia e de controle sobre as condições que possibilitam o acolhimento em um território. Tomadas dessa maneira, as fronteiras seriam menos um espaço de trânsito e mais um ponto de estagnação, de barricada, de impedimento. Seriam espaços em que a lógica do exame disciplinador reduziria o risco de pessoas "não autorizadas" no território, definindo por uma perspectiva fragmentária quais as características a serem controladas e, é claro, a quem caberia o exercício desse controle.

Para fazer frente a esse modo de funcionar nas práticas e na produção de conhecimento, a perspectiva da complexidade permite descontinuidades e campos de incertezas que facilitam a produção de novos e imprevisíveis acontecimentos. Aqui a questão que se coloca é muito mais aquela de fluxos e movimentos sejam eles quânticos ou migratórios - e as fronteiras são mais espaços de passagem que de contenção; passagem que é apenas uma probabilidade, um devir dos territórios, passagens que permitem habitar territórios fronteiriços, o entre, que comporta também o princípio da incompletude e da incerteza. A construção do saber complexo pressupõe o conhecimento de condições contingenciadoras que indicam maior ou menor probabilidade de ocorrência de determinado acontecimento. O que importa, então, é menos buscar as causas dos acontecimentos. Interessa conhecer as confluências que geram fluxos de possibilidades de variados acontecimentos.

A atuação em saúde mental na perspectiva de ruptura com a psiquiatria hegemônica, implica igualmente numa ruptura epistemológica que nos mobiliza para a produção de conhecimento marcada pela própria reinvenção profissional (YASSUI, 2006). Essa ruptura permite estabelecer a ação profissional num campo híbrido composto por múltiplos olhares e por linguagens variadas; um campo polifônico, em que emerge a polissemia dos atores em práticas profissionais não mais reguladas por fronteiras disciplinares. Assim, é possível sustentar a 
heterogênese das práticas em saúde mental a partir da instauração de um campo polifônico, uma vez que, "quanto mais diferentes são os que convivem num espaço limitado, mais idéias do mundo aí estarão para ser levantadas, cotejadas e, desse modo, tanto mais rico será o debate." (SANTOS, 2000, p. 13).

Por outro lado, o campo da saúde e, particularmente essas práticas híbridas em saúde mental, produzem rupturas e estabelecem vulnerabilidades que devem ser valorizadas e sustentadas enquanto espaços de passagem, cujos desdobramentos, superam as fronteiras disciplinares e permitem a migração de saberes e de fazeres que nascem na complexidade da vida cotidiana. É Milton Santos, novamente, quem nos diz que, ainda que individualmente possamos ter interesses diferentes, alguns fatores são decisivos na produção coletiva que,

(...) depende do exercício da solidariedade, indispensável ao trabalho e que gera a visibilidade do interesse comum. Tal comum não é obrigatoriamente o resultado de pactos explícitos nem de políticas claramente estabelecidas. A própria existência, adaptando-se a situações cujo comando freqüentemente escapa aos respectivos atores, acaba por exigir de cada qual um permanente estado de alerta, no sentido de apreender as mudanças e descobrir as soluções indispensáveis (MILTON SANTOS, 2000, p. 58).

Assim, buscar estabelecer novas possibilidades de trocas, novas economias no interior de um território comum aos trabalhadores da saúde mental, pode também nos conduzir à produção de territórios virtuais $\mathrm{e}$ improváveis, através da abertura para campos com os quais a saúde faz fronteira, como aqueles da cultura, das artes, da economia, do trabalho. Afinidades profissionais podem vir a constituir territórios híbridos, que comportem saberes diversos, construídos na perspectiva da complexidade da vida cotidiana.

\section{FINALIZANDO}

Em práticas de saúde mental, seria interessante buscarmos um campo de afinidades que nos aproxime e em que as fronteiras sejam lugares de troca entre territórios de habitantes diversos. Resta ainda o desafio de construir contextos de valorização frente a pessoas que estão em situação de desvalor, partindo de encontros entre singularidades, de gestos e de ações que se dão na confluência de acontecimentos complexos e que configuram a tensão de um território híbrido. Essa questão só poderá ser enfrentada se ousarmos atravessar as fronteiras que se constituem como limites colonizadores e que são tanto mais instransponíveis, quanto mais disciplinares.

$\mathrm{O}$ conceito de fronteira como limite disciplinador nos remete a ações ancoradas na lógica da exclusão, do ou/ ou e que é preciso superar, sob pena de estarmos dando crédito à fragmentação do saber e à economia de mercado, centrada na competição entre domínios como uma forma desejável de organização profissional. Trazer a discussão para o espaço da complexidade significa trabalhar na composição de forças, mais identificada com uma economia solidária, que se proponha a discutir estratégias de ação para transformar a realidade cotidiana comum a uma coletividade. Trata-se de discutir como operamos na prática para potencializar novas possibilidades de existência incluindo as diversidades subjetivas.

Essa discussão coloca-se, também, no âmbito da formação de profissionais de saúde, muitas vezes ainda pautada na afirmação das identidades profissionais, voltada de um lado com o fortalecimento disciplinar dos campos e de outro para a disputa pelo mercado de trabalho, que estão associados à valorização cada vez maior de formas verticais de organização do trabalho que não reconhecem legitimidade em outras maneiras de atuar que não aquela fragmentadora de sujeitos e saberes.

A concepção transdisciplinar e a defesa de uma confluência de saberes que contribui para a invenção de novos territórios híbridos -aqueles que abdicam das fronteiras enquanto zonas de controle, privilegiando a constituição de zonas de instabilidade fronteiriças - é, então, cada vez mais um desafio para a formação em saúde.

Milton Santos diz que cada ser humano, "é afinal definido pela soma dos possíveis que lhe cabem, mas também pela soma de seus impossíveis" (SANTOS, 2000: 63). Poderíamos dizer, em consonância com Milton Santos que o campo da saúde é definido pela soma dos possíveis que lhe cabem, mas também pela soma de seus impossíveis.

A necessidade de construirmos novas práticas em saúde mental e de formarmos profissionais para atuar nas novas instituições tem nos confrontado com a urgência de abandonarmos as verticalidades disciplinadoras, para criarmos horizontalidades solidárias que nos potencializem e que nos permitam avançar na produção de cotidianos e de práticas que se constituam em campos de forças que possam sustentar e estimular o desenvolvimento de novos impossíveis. 
LIMA, E. M. F. A.; GUIRARDI, M. I. G. Transdisciplinarity and hybrid practice in mental health. Rev. Ter. Ocup. Univ. São Paulo, v. 19, n. 3, p. 153-158, set./dez. 2008.

\begin{abstract}
Deistitutionalization process in metal health and the brazilian Psychiatric Reform send to the necessity of new practices in mental health attention. Create such practices, in order to face vulnerable life situations and also attend to complexity of life, considering personal characteristics and the subjective aspect of each history life, has been a challenge to mental health professionals committed with the construction of a service network that can be able to overcome the central place of psychiatric hospitals. Mental health staff have to face the challenge of reviewing their every day practices and, at the same time, to migrate from a mutiprofessional organization towards a transdisciplinar dynamic. This could lead the staff to a situation trough what they can inhabit boundaries as a strategy in order to establish hybrid territories in health practices. This paper aims to discuss this challenge, from the perspective of Brazilian's Psychiatric Reform, considering the demand of innovation that promotes new arrangements among different areas of knowledge within mental health field.
\end{abstract}

KEY WORDS: Mental health. Work.

\title{
REFERÊNCIAS
}

ALMEIDA FILHO, N. Transdisciplinaridade e o paradigma pós disciplinar na Saúde. Saúde e Sociedade, São Paulo v. 14, n. 3, p. 30-50, 2005.

AMARANTE, P. A (clínica) e a reforma psiquaiátrica. In: AMARANTE, P. (Org.). Archivos de saúde mental e atenção psicossocial. Rio de janeiro: Nau, 2003. p. 45-66.

BOURDIEU, P. Os usos sociais da ciência: por uma sociologia clínica do campo científico. São Paulo: UNESP, 2004.

CARVALHO, E. A. A declaração de Veneza e o desafio transdisciplinar. Revista Margem. São Paulo: Educ, 1992.

DELEUZE, G. Conversações. São Paulo: Editora 34, 2000.

FOUCAULT, M. Os anormais. São Paulo: Martins Fontes, 2001.

GALHEIGO, S. A transdisciplinaridade enquanto princípio e realidade das ações de saúde. Rev. Ter. Ocup. Univ. São Paulo, v. 10, n. 2/3, p. 49-54, 1999.

GUATTARI, F. Fundamentos éticos-políticos de interdisciplinaridade. In: RESENDE, B. (org.) Interdisciplinaridade. Rio de Janeiro: Tempo Brasileiro, 1992.

GUERRA, C. G. M. Transdisciplinaridade como (re) ligação entre ciência e cultura. Florianópolis: Uni\& Verso, 1998.

JUPIASSU, H. Interdisciplinaridade e patologia do saber. Rio de Janeiro: Imago, 1976.
LIMA. E. M. F. A. Terapia ocupacional: um território de fronteira? Rev. Ter. Ocup. Univ. São Paulo, v. 8, n. 2 , p. 98-102, 1997.

LIMA, E. M. P. A. Identidade e complexidade: composições no campo da terapia ocupacional. Rev. Ter. Ocup. Univ. São Paulo, v. 10, n. $2 / 3$, p. $42-46,1999$.

MÂNGIA, E. F.; SOUZA, D. C.; MATTOS, M. F.; HIDALGO, V. C. Acolhimento: uma postura, uma estratégia. Rev. Ter. Ocup. Univ. São Paulo, v. 13, n. 1, p. 15-21, 2002.

MORIN, E. Ciencia con consciencia. Barcelona: Del Hombre, 1984.

REIS, E. S. De corpos e afetos. Rio de Janeiro: Contra Capa, 2004.

SANDUVETTE, V. Sobre como e porque construir, (re)construir e avaliar projetos terapêuticos nos centros de atenção psicossocial (CAPS). Psicologia USP, São Paulo, v. 18, n. 1, p. 83-100, 2007.

SANTOS, B. S. Pela mão de Alice: o social e o político na pós modernidade. São Paulo: Cortez, 1996.

SANTOS, M. Por uma outra Globalização: do pensamento único à consciência universal. Rio de Janeiro: Record, 2000.

YASSUI, S. Rupturas e encontros: desafios da reforma psiquiátrica brasileira. Rio de Janeiro, 2006. Tese (Doutorado) - Escola Nacional de Saúde Pública da Fundação Oswaldo Cruz. 